\title{
Neuron Specific Enolase in Children with Diabetic Ketoacidosis: Does it Correlate with Impaired Consciousness and Disease Severity?
}

Eman Gamal Baz ${ }^{1}$, Saffaa M. Elalawi ${ }^{2}$, Mervat Atfy ${ }^{1}$, Tarek A. Abdelaziz ${ }^{1}$

Departments of ${ }^{1}$ Pediatric Medicine and ${ }^{2}$ Clinical Pathology, Faculty of Medicine,

Zagazig University, Zagazig, Egypt

*Corresponding author: Saffaa M. Elalawi, Mobile: (+20) 01212849069, E-Mail: saffaaalawi@yahoo.com

\begin{abstract}
Background: Diabetes ketoacidosis (DKA) is the leading cause of death in children with diabetes, especially when it is complicated by cerebral edema. The predictors of CNS dysfunction/injury are largely unknown. In many neurological disorders, neuron-specific enolase (NSE) is a marker of neuronal damage.

Objective: This study aimed to investigate the role of serum neuron-specific enolase as a marker of neuronal damage in patients with DKA.

Patients and methods: A cross-sectional study with 90 DKA patients (aged $9.58 \pm 2.89$ years) presenting to Pediatric Intensive Care Unit (PICU), Children Hospital Zagazig University. Patients subjected to clinical history and examination including Glasco coma scale (GCS), blood glucose, serum electrolytes, blood PH and computed tomography of the brain for children with disturbed consciousness. Blood NSE at admission (baseline point) and after 24 hours of starting treatment of DKA (2-time points).

Results: There was a significant difference between NSE level on admission and NSE level 24 hours after start of treatment. Patients with low GCS scores had higher serum NSE at baseline and 2-time points than those with normal CGS $(\mathrm{P}=0.001 ; \mathrm{P}=0.053)$. Patients with moderate and severe DKA had higher NSE at baseline and 2-time points in comparison with those with mild DKA ( $\mathrm{P}=0.001 ; \mathrm{P}=0.098)$.

Conclusions: Children with moderate to severe DKA and impaired consciousness had higher serum NSE. The high levels of NSE in patients with abnormal GCS, in the absence of cerebral edema on brain imaging indicate that NSE is a reliable marker of neuronal injury.
\end{abstract}

Keywords: Diabetic ketoacidosis, Neuron-specific enolase, Impaired consciousness.

\section{INTRODUCTION}

Diabetic ketoacidosis (DKA) occurs in 30\% of children with Type-I Diabetes Mellitus (T1DM) at diagnosis, while many children develop DKA as the disease progresses ${ }^{(1)}$. DKA occurs due to a lack of adequate insulin in the body. In the absence of insulin, the glucagon levels rise, releasing free fatty acids from adipose tissue and amino acids from muscle cells (2). DKA causes several abnormal processes within the body, including fluid shifts, decreased perfusion, and deranged $\mathrm{pH}$, all of which affect many functions and cause electrolyte imbalances. Consequently, many organs and body systems are affected ${ }^{(3)}$. Brain injury has been shown to result from DKA, although its exact pathogenesis is not known. Subclinical cerebral edema is prevalent in children with DKA, and frank cerebral edema occurs in 0.5 to $1 \%$ of children. In the past, cerebral edema resulting from DKA was believed to be the result of overaggressive fluid resuscitation and loss of brain osmotic homeostasis. Recently, this theory has been challenged. It is now thought that cerebral hypoperfusion followed by reperfusion injury may cause the cytotoxic and vasogenic edema seen in patients with cerebral edema from DKA ${ }^{(4)}$.

Neuronal-derived proteins (such as neuronspecific enolase) have been quantified in peripheral samples (blood and cerebrospinal fluid) as measures of brain damage/injury at the clinical and experimental levels. Neuron-specific enolase (NSE) is an enzyme of the cytoplasmic glycolytic pathway that is found in neurons and neuroendocrine tissue and is elevated in the blood after these cells die. In several studies, it has been established that higher serum or cerebrospinal fluid levels of NSE represent a higher vulnerability to traumatic injury, hypoxic-ischemic injury, and neurodegeneration ${ }^{(5)}$.

As a result, an early marker that can be easily measured in the blood and coincides with clinical decompensation for diabetic children could be useful for adjusting treatment strategies to minimize neurologic injury during DKA presentation. NSE has been studied as a brain injury biomarker in traumatic brain injury, but studies assessing its value in pediatric DKA are very few ${ }^{(5,6,7,8)}$. This study investigated serum concentration of NSE in children presenting with DKA upon PICU admission and after 24 hours of the start of treatment, as well as exploring the association between NSE and both impaired consciousness and severity of DKA.

\section{SUBJECTS AND METHODS}

This cross-sectional study was conducted at the Pediatrics and Clinical Pathology Departments of Zagazig University Hospital. Ninety pediatric patients presenting to the PICU of the University Children Hospital with a diagnosis of DKA. They were enrolled in the study over a 2-year-period. 90 patients (32 
males [35.6\%] and 58 females [64.4\%]), their mean age was $9.58 \pm 2.98$ years.

\section{Inclusion criteria:}

Patients aged between one and sixteen years, newly diagnosed or with an established diagnosis of T1DM, who admitted to the PICU due to DKA. DKA was diagnosed according to The American Diabetes Association, 2014 including hyperglycemia (blood glucose higher than $11 \mathrm{mmol} / \mathrm{L}$ or $\geq 200 \mathrm{mg} / \mathrm{dL}$ ) with a venous $\mathrm{pH}$ of $<7.3$ and/or bicarbonate $\left(\mathrm{HCO}_{3}\right)$ level of $<15 \mathrm{mmol} / \mathrm{L}$ and Ketonuria (urine ketones typically $\geq$ $2+)^{(9)}$. Diabetic ketoacidosis was classified according to severity of acidosis as mild (arterial $\mathrm{pH}<7.3$ ), moderate $(\mathrm{pH}<7.2)$, or severe diabetic ketoacidosis $(\mathrm{pH}<7.1)$ (10). Patients with DKA were assessed for consciousness using the Glasco coma scale (GCS) and then they were divided into those with normal GCS (GCS score $=15$ ) and those with GCS scores $<15$.

\section{Exclusion criteria:}

Diabetic patients with preexisting neurologic or neuro-developmental abnormality, those with hyperosmolar-hyperglycemic states, those with chronic complications of T1DM and those with hypoglycemic attacks. Additionally, we excluded patients outside the age group.'

\section{Data collection:}

Patients were subjected to medical history, including duration of T1DM since diagnosis, insulin treatment, compliance to treatment, and previous history of episodes of DKA or hypoglycemic attacks. Detailed clinical examinations including vital signs, Glasco coma scale (GCS) and neurological, cardiac, abdominal, and chest examination. The laboratory investigations included measurement of blood glucose levels, arterial blood gases, urine analysis for ketones, serum electrolytes, blood urea nitrogen, serum creatinine, and sepsis screen. Whole blood samples were taken at baseline (onset) and after 24 hours of starting treatment of diabetic ketoacidosis to measure serum levels of NSE. Computed Tomography of the brain was performed in children with disturbed levels of consciousness.

\section{Serum NSE quantification:}

Blood samples were taken by venipuncture into BD vacutainer ${ }^{\circledR}$ plastic plain tubes; EDTA tubes for complete blood count, heparinized tubes for arterial blood gases, and plain tubes. Plain tubes were permitted to clot for 30 minutes then were centrifuged at $1200 \mathrm{xg}$ for 10 minutes for separation of serum, $500 \mathrm{ul}$ of serum were divided into 2 Eppendorf tubes for Eliza assays (preserved into -80 deep freeze till analysis) while the rest of serum was used for measurement of blood glucose levels, serum electrolytes (sodium, calcium, and potassium), blood urea nitrogen and serum creatinine were performed on the Cobas 8000 Modular Analyzer series [C702 Module for chemistry tests and ISE Module for serum electrolytes (Roche Diagnostics, Mannheim, Germany)]. Neuron-specific enolase enzyme-linked immunosorbent assay kits (ELISA) were marketed with the brand name UBI MAGIWEL enzyme immunoassay-neuron specific enolase (UBI United Biotech Inc., Cat. No.: CM-901, Mountain View, CA). Hemolytic specimens were discarded because lysis of erythrocytes and platelets influence the serum NSE level.

\section{Ethical Approval:}

The research protocol was approved by the Institutional Review Board (IRB) of Zagazig University Academic and Ethical Committee. Written informed consents were taken from the parents of enrolled patients before being included in this study. This work has been carried out in accordance with The Code of Ethics of the World Medical Association (Declaration of Helsinki) for studies involving humans.

\section{Statistical analysis}

Data were statistically analyzed using IBM SPSS Statistics for Windows, version 25.0. (Armonk, NY: IBM Corp). Therefore, data were presented as means \pm standard deviation, and the categorical data were described using frequencies and percentages. Differences between the groups were evaluated by an independent sample t-test. Correlation regression analysis was used to determine the clinical, and laboratory factors that were significantly associated with high levels of NSE 24 hours after starting treatment. For all tests, values of $(\mathrm{P} \leq 0.05)$ were considered statistically significant.

\section{RESULTS}

A total of 90 patients presenting to the PICU with a diagnosis of DKA were enrolled in the study, including 38 patients $(42.2 \%)$ who were newly diagnosed with T1DM, whereas 52 patients $(57.8 \%)$ had an established diagnosis of T1DM. In the 90 patients, 32 [35.6\%] were males and 58 [64.4\%]) were females. The mean age of patients was $9.58 \pm 2.98$ years, and $35.6 \%$ of patients had previous episodes of DKA. A statistically significant difference between the mean NSE level on admission (baseline point) (14.55 \pm $3.5 \mathrm{ug} / \mathrm{L})$ and the mean level 24 hours after the start of treatment (2-time point) $(29.5 \pm 6.8 \mathrm{ug} / \mathrm{L})$ was found (P $<0.001)$. Those patients with GCS below 15 were 57 patients (63.4\%). Sixty-six patients (73.4\%) had moderate and severe DKA, and other clinical and laboratory characteristics were shown in table (1). 
Table (1): Demographic, clinical, and laboratory characteristics of the studied children with DKA

\begin{tabular}{|c|c|}
\hline The studied group & $\mathrm{N}=90(100 \%)$ \\
\hline $\begin{array}{l}\text { Gender } \\
\text { Males N (\%) } \\
\text { Females N (\%) } \\
\end{array}$ & $\begin{array}{l}32(35.6 \%) \\
58(64.4 \%)\end{array}$ \\
\hline $\begin{array}{l}\text { Age (years) } \\
\text { Mean } \pm \text { SD }\end{array}$ & $9.58 \pm 2.98$ \\
\hline $\begin{array}{l}\text { Classification of children } \\
\text { according to the onset of T1DM } \\
\text { Newly diagnosed T1DM } \\
\text { An established diagnosis of } \\
\text { T1DM }\end{array}$ & $\begin{array}{l}38(42.2 \%) \\
52(44 \%)\end{array}$ \\
\hline $\begin{array}{l}\text { Blood glucose level on } \\
\text { admission }(\mathrm{mg} / \mathrm{dL}) \\
\text { Mean } \pm \mathrm{SD}\end{array}$ & $493.43 \pm 98.2$ \\
\hline $\begin{array}{l}\text { Duration of T1DM since } \\
\text { diagnosis (years) } \\
\text { Mean } \pm \text { SD } \\
\end{array}$ & $5.3 \pm 2.3$ \\
\hline $\begin{array}{l}\text { Previous history of episodes of } \\
\text { DKA }\end{array}$ & $32(35.6 \%)$ \\
\hline $\begin{array}{l}\text { Classification of children } \\
\text { according to GCS at } \\
\text { presentation } \\
\text { GCS score }=15 \\
\text { GCS score }<15 \\
\end{array}$ & $\begin{array}{l}33(36.6 \%) \\
57(63.4 \%)\end{array}$ \\
\hline $\begin{array}{l}\text { Classification of children } \\
\text { according to the severity of } \\
\text { DKA } \\
\text { Mild } \\
\text { Moderate/severe } \\
\end{array}$ & $\begin{array}{l}24(26.6 \%) \\
66(73.4 \%)\end{array}$ \\
\hline $\begin{array}{l}\text { PH } \\
\text { Mean } \pm \text { SD }\end{array}$ & $7.11 \pm 0.13$ \\
\hline $\begin{array}{l}\text { Bicarbonate }(\mathrm{mEq} / \mathrm{L}) \\
\text { Mean } \pm \text { SD }\end{array}$ & $9.48 \pm 2.96$ \\
\hline $\begin{array}{l}\text { Sodium }(\mathrm{mEq} / \mathrm{L}) \\
\text { Mean } \pm \text { SD }\end{array}$ & $132.8 \pm 10.3$ \\
\hline $\begin{array}{l}\text { Potassium }(\mathrm{mEq} / \mathrm{L}) \\
\text { Mean } \pm \text { SD }\end{array}$ & $4.36 \pm 0.83$ \\
\hline $\begin{array}{l}\text { Blood urea nitrogen }(\mathrm{mg} / \mathrm{dl}) \\
\text { Mean } \pm \text { SD }\end{array}$ & $14.5 \pm 3.39$ \\
\hline $\begin{array}{l}\text { Serum osmolarity }(\mathrm{mmol} / \mathrm{L}) \\
\text { Mean } \pm \text { SD }\end{array}$ & $329.18 \pm 18.6$ \\
\hline $\begin{array}{l}\text { Creatinine }(\mathrm{mg} / \mathrm{dL}) \\
\text { Mean } \pm \text { SD }\end{array}$ & $0.8 \pm 0.13$ \\
\hline $\begin{array}{l}\text { Brain imaging }(\mathbf{C T}) \\
\text { Normal } \\
\text { Abnormal } \\
\text { N/A }\end{array}$ & $\begin{array}{l}57(63.4 \%) \\
0(0 \%) \\
33(36.6 \%)\end{array}$ \\
\hline $\begin{array}{l}\text { NSE }(\mathrm{ug} / \mathrm{L}) \\
\text { Baseline serum level (Mean } \pm \\
\text { SD) } \\
\text { Serum level } 24 \mathrm{~h} \text { after the start of } \\
\text { treatment (Mean } \pm \text { SD) }\end{array}$ & $\begin{array}{c}14.55 \pm 3.5 \\
29.6 \pm 5.7 \\
\mathbf{P}<\mathbf{0 . 0 0 1} \\
(\mathbf{H S})^{* *}\end{array}$ \\
\hline \multicolumn{2}{|c|}{$\begin{array}{l}\text { DKA; Diabetic Ketoacidosis, GCS; Glasgow Coma } \\
\text { Scale , NSE; Neuron Specific Enolase } \\
\text { **Highly significant difference }(P<0.001) \\
\quad \text { Compared to patients with normal GCS score } \\
\text { those with low GCS scores had higher serum levels }\end{array}$} \\
\hline
\end{tabular}

NSE at baseline and 2-time points $(\mathrm{P}=0.001 ; \mathrm{P}=0.053)$ as shown in table (2).

Table (2): Serum levels of NSE of the studied children in comparison to the GCS

\begin{tabular}{|c|c|c|c|}
\hline \multirow{2}{*}{$\begin{array}{l}\text { Classification } \\
\text { of children } \\
\text { according to } \\
\text { the GCS score }\end{array}$} & \multicolumn{2}{|c|}{ Levels of NSE (ug/L) } & \multirow{2}{*}{$\begin{array}{c}\text { P- } \\
\text { value }\end{array}$} \\
\hline & $\begin{array}{l}\text { Baseline } \\
\text { serum } \\
\text { level } \\
\text { (Mean } \pm \\
\text { SD) }\end{array}$ & $\begin{array}{c}\text { Serum level } \\
24 \mathrm{~h} \text { after } \\
\text { the start of } \\
\text { treatment } \\
\text { (Mean } \pm \text { SD) }\end{array}$ & \\
\hline $\begin{array}{l}\text { GCS score <15 } \\
\mathrm{N}=57(63.4 \%)\end{array}$ & $17.3 \pm 8.5$ & $23.5 \pm 6.9$ & $\begin{array}{c}\mathbf{0 . 0 0 1} \\
*(\mathbf{S})\end{array}$ \\
\hline $\begin{array}{l}\text { GCS score }=15 \\
\mathrm{~N}=33(36.6 \%)\end{array}$ & $5.16 \pm 2.8$ & $6.81 \pm 0.3$ & $\begin{array}{l}0.053 \\
\text { (NS) }\end{array}$ \\
\hline
\end{tabular}

According to DKA severity, patients with moderate and severe DKA had higher serum levels of NSE at baseline and 2-time points in comparison with those with mild DKA ( $\mathrm{P}=0.001 ; \mathrm{P}=0.098)$ as shown in table (3).

Table (3): Serum levels of NSE of the Studied Children in comparison to the severity of DKA

\begin{tabular}{|c|c|c|c|}
\hline \multirow{2}{*}{$\begin{array}{l}\text { Classification } \\
\text { of children } \\
\text { according to } \\
\text { the severity } \\
\text { of DKA }\end{array}$} & \multicolumn{2}{|c|}{ Levels of NSE (ug/L) } & \multirow{2}{*}{$\begin{array}{c}\text { P- } \\
\text { value }\end{array}$} \\
\hline & $\begin{array}{c}\text { Baseline } \\
\text { serum level } \\
\text { (Mean } \pm \\
\text { SD) }\end{array}$ & $\begin{array}{l}\text { Serum level } \\
24 \mathrm{~h} \text { after the } \\
\text { start of } \\
\text { treatment } \\
(\text { Mean } \pm \mathrm{SD})\end{array}$ & \\
\hline $\begin{array}{l}\text { Moderate/sev } \\
\text { ere DKA } \\
\mathrm{N}=66(73.4 \%)\end{array}$ & $19.2 \pm 8.1$ & $28.5 \pm 7.8$ & $\begin{array}{c}\mathbf{0 . 0 0 1} \\
*(\mathbf{S}) \\
\end{array}$ \\
\hline \begin{tabular}{|l} 
Mild DKA \\
$\mathrm{N}=24$ \\
$(26.6 \%)$
\end{tabular} & $8.4 \pm 3.3$ & $8.8 \pm 0.7$ & $\begin{array}{c}0.098 \\
\text { (NS) }\end{array}$ \\
\hline
\end{tabular}

Significant positive correlations were reported between serum levels of NSE at 24 hours after starting treatment of DKA and baseline NSE level $(\mathrm{r}=0.75 ; \mathrm{P}=$ $0.0001)$, duration of diabetes $(\mathrm{r}=0.45 ; \mathrm{P}=0.04)$ and initial blood glucose level $(r=0.72 ; P=0.002)$, whereas significant negative correlations were reported with age $(\mathrm{r}=-0.68 ; \mathrm{P}=0.001)$, GCS scores $(\mathrm{r}=-0.73 ; \mathrm{P}=$ $0.0001) \mathrm{PH}$ level (severity of acidosis) $(\mathrm{r}=-0.69 ; \mathrm{P}=$ $0.024)$ and bicarbonate level $(\mathrm{r}=-0.45 ; \mathrm{P}=0.03)$ as shown in table (4). 
Table (4): Correlation between serum levels of NSE after $24 \mathrm{~h}$ of treatment and clinical and laboratory parameters in diabetic children with diabetic ketoacidosis

\begin{tabular}{|l|c|c|}
\hline \multicolumn{1}{|c|}{ Variable } & R & P-value \\
\hline $\begin{array}{l}\text { Serum NSE on admission } \\
\text { (baseline point) }\end{array}$ & 0.75 & $\mathbf{0 . 0 0 0 1} *(\mathbf{H S})$ \\
\hline GCS score & -0.73 & $\mathbf{0 . 0 0 0 1} * *(\mathbf{H S})$ \\
\hline Age & -0.68 & $\mathbf{0 . 0 0 1} * \mathbf{S})$ \\
\hline Duration of diabetes & 0.31 & $\mathbf{0 . 0 4}$ (S) \\
\hline Blood sugar on admission & 0.72 & $\mathbf{0 . 0 0 2} *(\mathbf{S})$ \\
\hline PH & -0.69 & $\mathbf{0 . 0 2 4} *(\mathbf{S})$ \\
\hline Bicarbonate & -0.45 & $0.03 *(\mathbf{S})$ \\
\hline
\end{tabular}

GCS; Glasgow Coma Scale, NS; Not Significant, NSE; Neuron Specific Enolase, r; Pearson correlation coefficient, S; Significant *Statistically significant difference $(P<0.05) * *$ Highly significant difference $(P<0.001)$

Analysis of multiple regression for factors associated with elevated basal levels of neuron specific enolase determined significant association with levels of GCS $(\mathrm{P}=0.001)$, random serum glucose $(\mathrm{P}=0.003)$, $\mathrm{pH}(\mathrm{P}=0.039)$, and bicarbonate $(\mathrm{P}=0.009)($ Table 5).

Table (5): Multiple regression analysis of NSE of factors associated with elevated levels of NSE

\begin{tabular}{|c|c|c|c|}
\hline Variable & $\begin{array}{c}\text { Standardized } \\
\text { Coefficients } \\
\text { Beta } \\
\end{array}$ & $\mathbf{t}$ & P-value. \\
\hline GCS score & -.285 & $\overline{-} \overline{436}$ & $0.001 *(S)$ \\
\hline $\begin{array}{l}\text { Blood sugar } \\
\text { on } \\
\text { admission }\end{array}$ & .217 & 3.136 & $0.003 *(S)$ \\
\hline $\mathrm{PH}$ & -.193 & $\begin{array}{c}- \\
2.116\end{array}$ & $0.039 *(S)$ \\
\hline Bicarbonate & -.250 & $\overline{-}$ & $0.009 *(S)$ \\
\hline Age & .081 & 1.424 & $\begin{array}{l}\mathbf{0 . 1 6 1 *}^{*} \\
\text { (NS) }\end{array}$ \\
\hline $\begin{array}{l}\text { Duration of } \\
\text { diabetes }\end{array}$ & .074 & 1.445 & $\begin{array}{c}\mathbf{0 . 1 5 5} \\
(\mathrm{NS})\end{array}$ \\
\hline \multicolumn{4}{|c|}{$\begin{array}{c}\text { GCS; Glasgow Coma Scale, } \\
\text { NSE; Neuron Specific Enolase. }\end{array}$} \\
\hline $\begin{array}{l}\text {; Significant } \\
(P<0.05)\end{array}$ & $\begin{array}{l}\text { *Statistically sig } \\
\text { **Highly signific }\end{array}$ & ant $d$ & $\begin{array}{l}\text { nce } \\
(P<0.001)\end{array}$ \\
\hline
\end{tabular}

\section{DISCUSSION}

In diabetic children, DKA is the leading cause of PICU admissions. Hyperglycemia, osmotic diuresis, and metabolic acidosis are caused by insulin resistance or insulin deficiency. Severe acidosis can lead to CNS dysfunction as well as serious organ dysfunction. Children with severe DKA often exhibit altered mental status ${ }^{(9)}$. Neuronal damage in DKA needs to be measured promptly and accurately to determine the prognosis of functional outcomes. CT scan can identify structural damage in the brain, but it can miss the neurophysiological changes. Neuronal, axonal, and astroglial biomarkers detected in serum may aid in the prediction of clinical outcomes in critically ill patients. A simple plasma test would be extremely useful for neuromonitoring of patients at high risk of neurologic injury such as children presented with DKA ${ }^{(10,11, \text { and 12) }}$.

NSE is found primarily in neurons and neuroendocrine cells, and in response to various forms of brain injury, it is released into the CSF and blood, and it can serve as an indicator of ongoing neuronal damage. The biological half-life of NSE is longer than $20 \mathrm{~h}$, and serum levels of $>10$ microg/l are pathological. NSE is commonly used to predict outcomes after traumatic brain injuries (TBIs) and cardiac arrest. In addition, serum NSE has been shown to rise in cases of delirium, seizures, status epilepticus, and meningitis $(\mathbf{1 3}, \mathbf{1 4}, \mathbf{1 5}, \mathbf{1 6}$, and 17).

There was a statistically significant difference between the mean NSE level on admission (14.55 \pm $3.5 \mathrm{ug} / \mathrm{L})$ and the mean level 24 hours after the start of treatment $(29.6 \pm 8.7 \mathrm{ug} / \mathrm{L})(\mathrm{P}<0.001)$. The present study found that NSE levels increased before and during diabetic ketoacidosis correction. These findings are consistent with Elshorbagy et al. ${ }^{(18)}$ who found higher serum concentrations of NSE in the DKA group at the three-time points: admission $(13.9 \pm 2.8 \mathrm{ng} / \mathrm{mL}), 12$ hours $(27.8 \pm 2.3 \mathrm{ng} / \mathrm{mL})$, and 24 hours $(36.7 \pm 5.6$ $\mathrm{ng} / \mathrm{mL}$ ) after starting treatment compared to children with T1DM without DKA $(10.2 \pm 2.2 \mathrm{ng} / \mathrm{mL})$ and healthy controls $(5.17 \pm 1.5 \mathrm{ng} / \mathrm{mL})$. Similarly, Hamed et $\boldsymbol{a l} .{ }^{(5)}$ found a significant increase in serum levels of NSE at three-time points: baseline $(14.6 \pm 3.2 \mathrm{ug} / \mathrm{L}), 12$ $\mathrm{h}$ after the start of therapy $(29.7 \pm 2.12 \mathrm{ug} / \mathrm{L})$, and $24 \mathrm{~h}$ $(38.5 \pm 6.82 \mathrm{ug} / \mathrm{L})$ after the start of treatment of children with DKA.

According to our findings, the persistence of higher levels of NSE $24 \mathrm{~h}$ after starting DKA treatment suggests that neuronal injury may recover partially but not completely after the episodes of DKA, and therefore, repeated episodes of DKA may result in progressive neuronal injury. In addition, the healing process in neurological tissues is known to be relatively slow, so persistent NSE elevations might be expected after 24 hours of DKA. NSE levels are high during the critical period when acute complications of DKA have been reported ${ }^{(5,18)}$. In previous studies, NSE has been found in higher concentrations in patients with diabetes with and without overt neurological complications, and its presence is associated with increased oxidative stress and neuronal apoptosis. The multiple metabolic abnormalities that occur during DKA, including hyperglycemia, ketosis, acidosis, hypocapnia, and dehydration may cause oxidative stress, abnormal lipid peroxidation, neuroinflammation, and necrotic and apoptotic loss of neurons ${ }^{(5,19)}$.

In individuals with intact blood brain barrier (BBB), brain-derived proteins such as NSE do not cross the BBB. NSE levels have been used as a marker for brain injury with disruption of the BBB. It has been 
shown by Vavilala et al. ${ }^{(20)}$ that whole-brain and regional BBB permeability increase during DKA treatment. The exact mechanism of the increase in BBB permeability is not known, but it may be caused by the DKA-induced inflammatory response resulted in an immunologic cascade that disrupted tight endothelial junctions. Additionally, hyperglycemia, matrix metalloproteinase activity, and insulin administration are all associated with increased BBB permeability. As long as the damage continues and NSE is washing out of the brain tissue, serum levels of NSE should rise ${ }^{(\mathbf{2 1}, \mathbf{2 2})}$. Our results are consistent with a previous study reporting evidence of neuronal injury without brain edema. In an adolescent with T1DM and recurrent episodes of DKA without clinically evident cerebral edema, Wootton-Gorges et al. ${ }^{(23)}$ observed a reduction in $\mathrm{N}$-acetyl aspartate/creatine ratio as an indication of irreversible brain damage. In contrast to our findings, Çath et al. ${ }^{(21)}$ found no significant difference in NSE levels between the DKA, T1DM, and healthy control groups, and did not change significantly during DKA treatment. These unexpected results of their study may be explained by fewer cases in the DKA, T1DM, and healthy control groups.

In this study, the high percentage of patients $(63.4 \%)$ presenting with depressed mental status as indicated by GCS < 15 was unexpected. There is considerable evidence that DKA patients commonly have some degree of cerebral injury or dysfunction at the time of presentation, though it is often subclinical. Therefore, identifying patients at risk for cerebral injury is important and the scope of the problem is much broader than that represented by the small percentage of patients with overt cerebral edema ${ }^{(24)}$. In the current study, compared to patients with normal GCS scores, those with low GCS scores had higher serum levels of NSE at baseline and 2-time points and according to DKA severity, patients with moderate and severe DKA had higher serum levels of NSE at baseline and 2-time points in comparison with those with mild DKA, suggesting that the severity of acidosis was the main factor responsible for the increase in NSE levels. According to Hamed $\boldsymbol{e t} \boldsymbol{a l} .{ }^{(5)}$ in comparison with patients with normal GCS scores and those with mild DKA, those with low GCS scores and those with moderate to severe DKA had significantly higher levels of neuron-specific enolase at 3-time points. The difference between the DKA group with normal GCS scores and healthy controls was not significant. Also, Elshorbagy $\boldsymbol{e t} \boldsymbol{a l}{ }^{(\mathbf{1 8 )})}$ concluded that patients with low GCS scores had significantly higher concentrations of NSE at the three-time points compared to patients with normal GCS scores, and patients with severe DKA had significantly higher concentrations of NSE at each time point compared to patients with moderate and mild DKA. However, the difference between the mild DKA group and healthy controls was not significant. On the other hand, Çath et al. (21) found no significant difference in NSE levels between DKA patients with low and normal GCS. Based on our findings, we concluded that elevated NSE levels may indicate neuronal injury in patients with abnormal GCS despite the lack of radiological findings in CT scans.

In this current study, we found significant positive correlations between serum levels of NSE after starting treatment of DKA and baseline NSE level, duration of diabetes, and initial blood glucose level, whereas significant negative correlations were reported with age, GCS scores, and severity of acidosis. These findings are in accordance with Elshorbagy et al. ${ }^{(\mathbf{1 8 )}}$ who found that the risk factors of higher serum concentrations of NSE in children with DKA were younger age, lower GCS score, higher degrees of hyperglycemia, longer duration of illness, and more severe acidosis and ketosis. Hamed et $\boldsymbol{a l} .{ }^{(5)}$ found significant positive correlations between levels of NSE at 24 hours after starting treatment of DKA with random serum glucose level, duration of T1DM, and levels of NSE at baseline, whereas significant negative correlations were reported with age, GCS score, $\mathrm{pH}$, and bicarbonate. According to previous studies, the predictors of higher levels of neuronspecific enolase in diabetic ketoacidosis seemed to be young age, severe hyperglycemia, acidosis, and ketosis $(\mathbf{2 5}, \mathbf{2 6}$. There are many factors associated with higher levels of NSE during DKA, but none of these variables has been singled out as the most important determining factor ${ }^{(5,25}$, and 26). However, the degree of acidosis was the most important determining factor of an impaired level of consciousness in children with DKA without cerebral edema ${ }^{(28)}$. Study strengths include the fact that NSE can obtain more precise measurements of neuronal damage during DKA treatment in addition to clinical examination, which is important for determining the prognosis of functional outcomes. Our ability to recognize and diagnose DKA patients with neuronal damage may be improved. Moreover, the development of point-of-care tests would be vital for providing clinicians who treat DKA patients with real-time information. Point-of-care, rapid plasma NSE testing could become an adjunct to other neuromonitoring methods commonly used in PICUs, allowing clinicians to stratify patients based on their risk for neurologic injury due to DKA. NSE serum testing could act as a trigger for neuroimaging (e.g., brain MRI) and provide insight into neuroprotective interventions, as well as predict long-term outcomes. Furthermore, NSE may be used as real-time entry criteria for future clinical trials (29).

Our study had several limitations that must be considered. The first challenge is defining and detecting neurologic injuries in children. Although the GCS score is more objective, it may not be sensitive enough to detect neurologic injuries. Furthermore, no control or diabetic groups were selected for further comparative analysis of the results. Due to ethical concerns, NSE in the cerebrospinal fluid was not measured. Further studies, including long-term neuropsychological 
follow-up, will need to be performed to confirm these findings. Upon obtaining the appropriate funding, we will follow a subset of patients for the purpose of determining cognitive outcomes over time and assessing the relationship between cognitive impairment and these markers and evidence of CNS injury at the time of presentation with DKA.

\section{CONCLUSION}

Children with moderate to severe DKA and impaired consciousness have higher serum levels of NSE. The high levels of NSE in patients with abnormal GCS, in the absence of cerebral edema on brain imaging, and the positive correlation between NSE and severity of acidosis indicate that NSE is a reliable marker for neuronal injury.

\section{Financial support and sponsorship: Nil. \\ Conflict of interest: Nil.}

\section{REFERENCES}

1. Abbas Q, Arbab S, Haque A et al. (2018): Spectrum of complications of severe DKA in children in pediatric Intensive Care Unit. Pak J Med Sci., 34 (1): 106-109.

2. Raghupathy $\mathbf{P}$ (2015): Diabetic ketoacidosis in children and adolescents. Indian J Endocrinol Metab., 19 (1): 55-57.

3. Bialo S, Agrawal S, Boney $\mathrm{C}$ et al. (2015): Rare complications of pediatric diabetic ketoacidosis. World $\mathbf{J}$ Diabetes, 6 (1): 167-174.

4. Levin D (2008): Cerebral edema in diabetic ketoacidosis Pediatr Crit Care Med., 9 (3): 320-329.

5. Hamed S, Metwalley K, Farghaly $H$ et al. (2017): Serum Levels of Neuron-Specific Enolase in Children with Diabetic Ketoacidosis. J Child Neurol., 32 (5): 475-481.

6. Papa L, Ramia M, Kelly J et al. (2013): Systematic review of clinical research on biomarkers for pediatric traumatic brain injury. J Neurotrauma, 30 (5): 324-338.

7. Daoud H, Alharfi I, Alhelali I et al. (2014): Brain injury biomarkers as outcome predictors in pediatric severe traumatic brain injury. Neurocrit Care, 20 (3): 427-435.

8. Kaya C, Ataş A, Aksoy N et al. (2015): Evaluation of PreTreatment and Post-Treatment S100B, Oxidant and Antioxidant Capacity in Children with Diabetic Ketoacidosis. J Clin Res Pediatr Endocrinol., 7 (2): 109113.

9. Rosner E, Strezlecki K, Clark J et al. (2015): Low thiamine levels in children with type 1 diabetes and diabetic ketoacidosis: a pilot study. Pediatr Crit Care Med., 16 (2): 114-118.

10. Yeung C, Bhatia R, Bhattarai B et al. (2020): Role of Salivary Biomarkers in Predicting Significant Traumatic Brain Injury: An Exploratory Study. Pediatr Emerg Care, 20: $10-15$.

11. Bembea M, Rizkalla N, Freedy J et al. (2015): Plasma Biomarkers of Brain Injury as Diagnostic Tools and Outcome Predictors After Extracorporeal Membrane Oxygenation. Crit Care Med., 43 (10): 2202-2211.

12. Prout A, Wolf M, Fink E (2017): Translating biomarkers from research to clinical use in pediatric neurocritical care: focus on traumatic brain injury and cardiac arrest. Curr Opin Pediatr., 29 (3): 272-279.

13. Haque A, Polcyn R, Matzelle D et al. (2018): New Insights into the Role of Neuron-Specific Enolase in Neuro-
Inflammation, Neurodegeneration, and Neuroprotection. Brain Sci., 8 (2): 33-37.

14. Raghu V, Horvat C, Kochanek P et al. (2021): Neurological Complications Acquired During Pediatric Critical Illness: Exploratory "Mixed Graphical Modeling" Analysis Using Serum Biomarker Levels. Pediatr Crit Care Med., 10: 1-9

15. Anderson B, Reilly J, Shashaty $M$ et al. (2016): Admission plasma levels of the neuronal injury marker neuron-specific enolase are associated with mortality and delirium in sepsis. J Crit Care, 36: 18-23.

16. Shaik J, Reddy K, Mohammed $N$ et al. (2019): Neuron specific enolase as a marker of seizure related neuronal injury. Neurochem Int., 131: 104-109.

17. Bartek J, Thelin E, Ghatan $\mathbf{P}$ et al. (2016): NeuronSpecific Enolase Is Correlated to Compromised Cerebral Metabolism in Patients Suffering from Acute Bacterial Meningitis; An Observational Cohort Study. PLoS One, 11 (3): $152-158$

18. Elshorbagy H, Barseem N, Elsadek A et al. (2019): Serum Neuron-specific Enolase and S100 Calcium-binding Protein B in Pediatric Diabetic Ketoacidosis. J Clin Res Pediatr Endocrinol., 11 (4): 374-387.

19. Li J, Yan M, Zhang Y et al. (2015): Serum neuron-specific enolase is elevated as a novel indicator of diabetic retinopathy including macular oedema. Diabet Med., 32 (1): 102-107.

20. Vavilala M, Richards T, Roberts J et al. (2010): Change in blood-brain barrier permeability during pediatric diabetic ketoacidosis treatment. Pediatr Crit Care Med., 11 (3): 332338.

21. Çath G, Anık A, Acar S et al. (2018): Brain injury markers: S100 calcium-binding protein $\mathrm{B}$, neuron-specific enolase and glial fibrillary acidic protein in children with diabetic ketoacidosis. Pediatr Diabetes, 19 (5): 1000-1006.

22. Tasker R, Acerini C (2014): Cerebral edema in children with diabetic ketoacidosis: vasogenic rather than cellular?. Pediatr Diabetes, 15 (4): 261-270.

23. Wootton-Gorges $\mathrm{S}$, Buonocore $\mathrm{M}$, Caltagirone $\mathrm{R}$ et al. (2010): Progressive decrease in $\mathrm{N}$-acetylaspartate/Creatine ratio in a teenager with type 1 diabetes and repeated episodes of ketoacidosis without clinically apparent cerebral edema: Evidence for permanent brain injury. AJNR Am J Neuroradiol., 31 (4): 780-781.

24. Nett S, Noble J, Levin D et al. (2014): Biomarkers and genetics of brain injury risk in diabetic ketoacidosis: A pilot study. J Pediatr Intensive Care, 3 (2): 59-66.

25. Cameron F, Scratch S, Nadebaum C et al. (2014): Neurological consequences of diabetic ketoacidosis at initial presentation of type 1 diabetes in a prospective cohort study of children. Diabetes Care, 37 (6): 1554-1562.

26. Glaser N, Ngo C, Anderson S et al. (2012): Effects of hyperglycemia and effects of ketosis on cerebral perfusion, cerebral water distribution, and cerebral metabolism. Diabetes, 61 (7): 1831-1837.

27. Glaser N, Bundros A, Anderson S et al. (2014): Brain cell swelling during hypocapnia increases with hyperglycemia or ketosis. Pediatr Diabetes, 15 (7): 484-493.

28. Nyenwe E, Razavi L, Kitabchi A et al. (2010): Acidosis: the prime determinant of depressed sensorium in diabetic ketoacidosis. Diabetes Care, 33 (8): 1837-1839.

Bembea M, Rizkalla N, Freedy J et al. (2015): Plasma biomarkers of brain injury as diagnostic tools and outcome predictors after extracorporeal membrane oxygenation. Crit Care Med., 43 (10): 2202-2211. 